\title{
Effect of compounds isolated from Filicium decipiens and Ventilago madraspatana against diabetic nephropathy in streptozotocin induced diabetic rats
}

\author{
C. Sasikala1, ${ }^{1}$, Yajaman Sudhakar ${ }^{2}$ \\ ${ }^{1}$ Research scholar, Department of Pharmacy, JNTUK, Kakinada, Andhrapradesh- 533003 \\ ${ }^{2}$ Government Polytechnic for Women, Kadapa- 516 002, Andhra Pradesh.
}

\begin{abstract}
Context: Diabetes mellitus is a group of syndromes characterized by hyperglycemia, altered metabolism of lipids, carbohydrates and proteins and an increased risk of complications from vascular diseases. Filicum decipiens Wight \& Arn., (Sapindaceae) and Ventilago madraspatana Gaertn., (Rhamnaceae) are traditionally used for diabetic and other different folk medical uses. Objective: The present study compares the antihperglycemic activity exerted by methanolic extracts of Filicum decipiens $(400 \mathrm{mg} / \mathrm{kg})$, Ventilago madraspatana $(400 \mathrm{mg} / \mathrm{kg})$, rutin $(100 \mathrm{mg} / \mathrm{kg})$, quercetin $(50 \mathrm{mg} / \mathrm{kg})$ and combined treatment of rutin with quercetin $(100 \mathrm{mg} / \mathrm{kg}+(50 \mathrm{mg} / \mathrm{kg})$ on diabetic rats. Material and methods: Methanolic extracts of Filicum decipiens and Ventilago madraspatana leaves were prepared and isolated by soxhlet and solubilization method. Rats were made diabetic by a single dose of streptozotocin $(45 \mathrm{mg} / \mathrm{kg}$ i.p.). The animals with fasting blood glucose level more than $250 \mathrm{mg} / \mathrm{dL}$ were given methanolic leaves extract of Filicum decipiens $(400 \mathrm{mg} / \mathrm{kg})$, Ventilago madraspatana $(400 \mathrm{mg} / \mathrm{kg})$, quercetin $(50 \mathrm{mg} / \mathrm{kg})$, rutin $(100 \mathrm{mg} / \mathrm{kg})$ and rutin with quercetin $(100 \mathrm{mg} / \mathrm{kg}+50 \mathrm{mg} / \mathrm{kg})$ were administered for 45 days and screened for antidiabetic activity. Results and discussion: After 45 days we observed that supplementation with combined dose of rutin and quercetin significantly $(p<0.05)$ decreased glycosylated hemoglobin $\left(\mathrm{HbA}_{1} \mathrm{C}\right)(6.01 \mathrm{mg} / \mathrm{g})$ and increased the levels of plasma insulin $11.98 \mu \mathrm{U} / \mathrm{mL}$, hemoglobin $12.12 \mathrm{~g} / \mathrm{dL}$, urea $42.16 \mathrm{mg} / \mathrm{dL}$, creatinine 1.41 $\mathrm{mg} / \mathrm{dL}$, plasma sodium $141.00 \mathrm{mEq} / \mathrm{L}$ and urinary potassium $5.11 \mathrm{mEq} / \mathrm{L}$ and decrease the activities of enzymatic antioxidant upon STZ treatment and also significantly $(p<0.05)$ reversed the altered levels and activities of above mentioned diabetic, renal and antioxidant markers in experimental rats as compared to their individual supplementation. Conclusion: Summed effect of quercetin with rutin seems to have a promising value for the development of a potent phytomedicine for diabetic nephropathy.
\end{abstract}

Key words: Filicum decipiens, Ventilago madraspatana, antioxidant and renal markers.

\section{INTRODUCTION}

Diabetes mellitus is a complex endocrine metabolic disorder. Globally, as of 2010, an estimated 285 million people had diabetes, with type 2 making up about $90 \%$ of the cases. ${ }^{1}$ Its incidence is increasing rapidly, and by 2030 , this number is estimated to almost double. India has more diabetics than any other country in the world, according to the International Diabetes Foundation. Clinically, the main consequence of hyperglycemia is secondary impairments in various tissues and organs. Some complications such as cardiovascular disease, kidney disease, retinopathy, and nervous system diseases result in substantial morbidity and mortality. $^{2}$

Diabetic nephropathy is a progressive, irreversible disease characterized by increasing blood pressure, micro albuminuria, proteinuria, and a continuous decline in glomerular filtration rate. There are several factors involved in the development of diabetic glomerulopathy but the main initiator of this disease is chronic hyperglycemia, which triggers increased production of reactive oxygen species, increasing oxidative stress and
DOI: 10.5530/ijper.49.2.11 Correspondence Address C. Sasikala

Research scholar, Department of Pharmacy, JNTUK, Kakinada, Andhrapradesh-533003 e.mail:sasivenkee@gmail. com

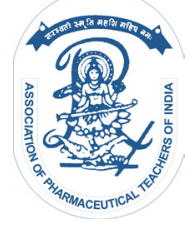

www.ijper.org 
favoring coagulation and fibrotic events. Hyperglycemia also sensitizes the vessel wall of efferent arterioles to the action of vasoconstrictors, which, together with an increase in vascular permeability, lead to hyper filtration. Also, in the progression of diabetic nephropathy persistent proteinuria, glomerular hypertrophy, mesangial expansion, and tubulointerstitial fibrosis occur, which lead to partial or total loss of renal function. ${ }^{3}$

Filicum decipiens and Ventilago madraspatana are traditionally used for diabetic, so the above findings instigate us to explore the summed effect of RUT/QUE isolated compounds from plants on the STZ-induced changes in the levels of glucose, insulin, $\mathrm{Hb}, \mathrm{HbA}_{1} \mathrm{C}$, on tent, and the activities of antioxidant enzymes and renal function indicators in STZ induced diabetic nephropathy.

\section{MATERIAL AND METHODS}

\section{Plant material - extraction and isolation}

The leaves of Filicum decipiens Wight \& Arn., (Sapindaceae) and Ventilago madraspatana Gaertn. (Rhamnaceae) were collected from Tirupati, Andra Pradash, India, on July, 2010. Identification and botanical authentication of plant was carried out at the Department of Botany, Sri Venkateswara University, Tirupathi by Dr. K. Madhava Chetty, where a voucher specimen was lodged. After collection, the leaves of Filicium decipiens and Ventilago maderaspatana were separated from other plant parts, dust and then washed with running tap water. The leaves of Filicium decipiens and Ventilago maderaspatana were shade dried at room temperature for 15 days and coarsely powdered. Then each plant powder (300 g) was extracted with methanol successively using Soxhlet apparatus for $16 \mathrm{~h}$. The solvent was evaporated to dryness in a rotary evaporator. The yield of the methanol extract were $25.6 \mathrm{~g}$ from Filicium decipiens and $20.67 \mathrm{~g}$ from Ventilago maderaspatana. Quercetin from Filicium decipiens and rutin from Ventilago maderaspatana were isolated by fraction and solubilization method. ${ }^{4}$

\section{Animal model}

The whole experiment was carried out according to the guidelines of the Committee for the Purpose of Control and Supervision of Experiments on Animals (CPCSEA), New Delhi, India, and approved by the Institutional Animal Ethical Committee (IAEC NUMBER: Ph.D/ COL/11/10-13). The study was conducted on 48 male albino Wistar rats weighing 180-220 g, obtained from the Central Animal House. They were housed in polypropylene cages $(47 \times 34 \times 20 \mathrm{~cm}$ ), (six rats per cage) lined with husk, renewed every $24 \mathrm{~h}$ under a $12: 12 \mathrm{~h}$ light dark cycle at around $22{ }^{\circ} \mathrm{C}$ and had free access to tap water and pellet diet (Pranav Agro Industries Limited, Maharashtra,
India). The pellet diet consists of $22.02 \%$ protein, $4.25 \%$ fat, $3.02 \%$ fiber, $7.5 \%$ ash, $1.38 \%$ sand silica, $0.8 \%$ calcium, $0.6 \%$ phosphorus, $2.46 \%$ glucose, $1.8 \%$ vitamins and $56.17 \%$ carbohydrates. It provided a metabolisable energy of $3600 \mathrm{kcal} / \mathrm{kg}$.

\section{Induction of experimental diabetes}

Streptozotocin (STZ) was freshly dissolved in citrate buffer (0.01 M, pH 4.5) and maintained on ice prior to use. The overnight fasted rats were made type 2 diabetic with a single intraperitoneal injection of STZ (50 $\mathrm{mg} / \mathrm{kg}$ ). Control rats were injected with citrate buffer alone. Diabetes was confirmed in the STZ-treated rats by measuring the fasting plasma glucose levels $72 \mathrm{~h}$ post injection. After an overnight fast, blood was withdrawn by sinocular puncture $(0.2 \mathrm{ml})$ from rats in tubes containing potassium oxalate and sodium fluoride as anticoagulant. Plasma was separated after centrifugation and glucose was estimated using a commercial glucose kit (Sigma Diagnostics Pvt. Ltd., Baroda, India). Rats with plasma glucose levels above $13.89 \mathrm{mmol} / \mathrm{L} \quad$ (250 $\mathrm{mg} / \mathrm{dl}$ ) were considered as diabetic and were used in the experiment.

\section{Experimental design}

The rats were divided into 8 groups comprising of 6 animals in each group as follows:

Group I: Normal rats.

Group II: RUT (100 mg/kg/day) and QUE (50 mg/ $\mathrm{kg} /$ day).

Group III: Diabetic control rats.

Group IV: Diabetic rats + MVM (400 mg/kg/day).

Group V: Diabetic rats + MFD (400 mg/kg/day).

Group VI: Diabetic rats + RUT (100 mg/kg/day).

Group VII: Diabetic rats + QUE (50 mg/kg/day).

Group VIII: Diabetic rats + RUT (100 mg/kg/day) and QUE $(50 \mathrm{mg} / \mathrm{kg} /$ day).

RUT and QUE were saturated in water and orally administered to rats using an intragastric tube daily for a period of 45 days.

\section{Termination of Study}

At the end of the experimental period, after an overnight fast, the rats were anaesthetize and sacrificed by cervical decapitation. Blood samples were collected in heparinized tubes, after $60 \mathrm{~min}$ rest in the supine position, and then centrifuged at $160 \times g$ for $10 \mathrm{~min}$ at $20^{\circ} \mathrm{C}$. Plasma was separated and stored at $-20{ }^{\circ} \mathrm{C}$ until assay. Kidneys was carefully dissected out, cleaned, weighed accurately and stored at $-80{ }^{\circ} \mathrm{C}$ until used.

\section{Analytical procedure}

Plasma glucose ${ }^{5}$ using a commercial kit (Sigma Diagnostics Pvt. Ltd., Baroda, India). Plasma insulin was assayed 
by an enzyme-linked immunosorbent assay (ELISA) method using a commercial kit (Catalog No.SP-401) from United Biotech Inc., Mountain View, CA, USA. Hemoglobin was estimated by the cyanmethemoglobin method. ${ }^{6-8} \mathrm{HbA}_{1 \mathrm{C}}$.

Renal function was defined by measuring urea, uric acid and creatinine concentration with standard commercial diagnostic kit (Span Diagnostics, Gujarat, India). Serum albumin contents were estimated by the method described by Reinhold. ${ }^{9}$ Sodium and potassium ion concentrations of the plasma and urine samples were measured using an electrolyte analyzer (Nova Electrolyte/ Chemistry Analyzers-Nova 4), Waltham MA, USA).

The kidney excised $(1 \mathrm{~g})$ was cut into small pieces and mixed with $3 \mathrm{~mL}$ Tris $\mathrm{HCl}(0.05 \mathrm{M}, \mathrm{pH}=7.6)$ buffer. The mixture was homogenized, allowed to stand on ice for few minutes, and then centrifuged for $15 \mathrm{~min}$ at $8000 \times g$ at $4{ }^{\circ} \mathrm{C}$. The supernatant stored in small aliquots at $-80{ }^{\circ} \mathrm{C}$ for further analysis. Lipid peroxidation as indicated by thiobarbituric acid reactive substances (TBARS) was measured using the method. ${ }^{10}$

Superoxide dismutase (SOD, EC. 1.15.1.1). ${ }^{1}$ Catalase (CAT, EC. 1.11.16). ${ }^{12}$ Glutathione reductase (GR, EC.1.6.4.2) was determined by the method of and Mannerik. ${ }^{13}$ Glutathione peroxidase (GPx, EC.1.11.1.9) activity was assayed by the method of and Gunzler. ${ }^{14}$ A known amount of the enzyme preparation was incubated with $\mathrm{H}_{2} \mathrm{O}_{2}$ and was determined using method. ${ }^{15}$

Measurement of non enzymic antioxidants reduced glutathione (GSH) was determined by the method of, ${ }^{16}$ based on the reaction with Ellman's reagent.

\section{Histology of kidney}

Kidneys were quickly removed after euthanasia, fixed in $10 \%$ buffered formalin for $48 \mathrm{hrs}$, dehydrated by passing successively in different concentrations of ethanolwater, cleaned in xylene, embedded in paraffin and they were sectioned (5-6 $\mu \mathrm{m}$ thickness) by microtome. Sections were stained with hematoxylin and eosin $(\mathrm{H}$ and E) dye and then mounted in a neutral deparaffinated xylene (DPX) medium using standard protocols. They were assessed using light microscopy and photographed.

\section{Data analysis}

The data are expressed as means \pm SD. Comparisons of the determined variables among all the grouped data for biochemical and physiological parameters were analyzed statistically using one way analysis of variance (ANOVA) followed by Duncan's multiple range test for post hoc analysis using the SPSS software package, version 11.01 for windows and line graphs were drawn using the sigma plot (version 10.0) software package. Statistical significance was defined as $p$ values less than 0.05 .

\section{RESULTS}

(Table 1) shows the levels of plasma glucose, insulin, $\mathrm{Hb}$ and $\mathrm{HbA}_{1 \mathrm{C}}$ in normal and experimental rats. In diabetic control rats, there was a significant $(\mathrm{p}<0.05)$ increase in the levels of plasma glucose and $\mathrm{HbA}_{1 \mathrm{C}}$ when compared to normal control rats. A single treatment with MVM, MFD, rutin or quercetin significantly $(p<0.05)$ reduced the concentrations of plasma glucose and $\mathrm{HbA}_{1 \mathrm{C}}$ respectively. On combined treatment with rutin and quercetin, a much greater fall in the concentrations of plasma glucose and $\mathrm{HbA}_{1 \mathrm{C}}$ were noticed than individual treatment. In diabetic control rats, there was a significant $(p<0.05)$ decrease in the levels of insulin and $\mathrm{Hb}$ concentration when compared to normal control rats. A single treatment with MVM, MFD arutin or quercetin significantly $(p<0.05)$ increased the concentrations of insulin and $\mathrm{Hb}$ respectively. On combined treatment with rutin and quercetin, a much greater increased in the concentrations of insulin and $\mathrm{Hb}$ was noticed than individual treatment.

(Table 2) shows the levels of serum urea, creatinine, albumin, sodium and potassium in normal and experimental rats. In diabetic control rats, there was a significant $(p<0.05)$ increase in the levels of serum urea, creatinine and plasma sodium when compared to normal control rats. A single treatment with MVM, MFD, rutin or quercetin significantly $(p<0.05)$ reduced the concentrations of serum urea, creatinine and plasma sodium respectively. On combined treatment with rutin and quercetin, a much greater fall in the concentrations of serum urea, creatinine and plasma sodium were noticed than individual treatment. In diabetic control rats, there was a significant $(p<0.05)$ decrease in the levels of albumin and plasma potassium when compared to normal control rats. A single treatment with MVM, MFD a rutin or quercetin significantly $(\phi<0.05)$ increased the concentrations of albumin and plasma potassium respectively. On combined treatment with rutin and quercetin, a much greater increased in the concentrations of albumin and plasma potassium was noticed than individual treatment.

(Table 3) shows the levels of urinary volume, urinary sodium and potassium in normal and experimental rats. In diabetic control rats, there was a significant $(p<0.05)$ increase in the levels of urinary potassium when compared to normal control rats. A single treatment with MVM, MFD, rutin or quercetin significantly $(p<0.05)$ reduced the concentrations of urinary potassium. On combined treatment with rutin and quercetin, a much greater fall in the concentrations of urinary potassium was noticed than individual treatment. In diabetic control rats, there was a significant $(p<0.05)$ decrease in the levels of urinary volume and urinary sodium when com- 
pared to normal control rats. A single treatment with MVM, MFD a rutin or quercetin significantly $(p<0.05)$ increased the concentrations of urinary volume and urinary sodium respectively. On combined treatment with rutin and quercetin, a much greater increased in urinary volume and urinary sodium was noticed than individual treatment.

(Table 4) shows the levels of kidney TBARS, superoxide dismutase, catalase, glutathione peroxidase and reduced glutathione in normal and experimental rats. In diabetic control rats, there was a significant $(p<0.05)$ increase in the levels of kidney TBARS when compared to normal control rats. A single treatment with MVM, MFD, rutin or quercetin significantly $(p<0.05)$ reduced the concentrations of kidney TBARS. On combined treatment with rutin and quercetin, a much greater fall in the concentrations of kidney TBARS was noticed than individual treatment. In diabetic control rats, there was a significant $(p<0.05)$ decrease in the levels of superoxide dismutase, catalase, glutathione peroxidase and reduced glutathione when compared to normal control rats. A single treatment with MVM, MFD arutin or quercetin significantly $(p<0.05)$ increased the concentrations of superoxide dismutase, catalase, glutathione peroxidase and reduced glutathione respectively. On combined treatment with rutin and quercetin, a much greater increased in superoxide dismutase, catalase, glutathione peroxidase and reduced glutathione was noticed than individual treatment.

(Figure 1) summarizes photomicrographs of the hematoxylin and eosin staining of kidney of the control and experimental rats. (Figure $1 \mathrm{a}$ and $1 \mathrm{~b}$ ) photomicrograph of renal sections stained with hematoxylin and eosin $(\mathrm{H}$ \& E) showed no histopathological changes in kidney of control group and rutin and quercetin treated group. (Figure 1c) kidney sections of diabetic control group showed hypertrophied distorted glomeruli and dilated tubules with thick basement membranes. A single treatment with MVM, MFD, rutin or quercetin (Figure: 1d, 1e, 1f, and 1g) showed some interstitial fibrosis and inflammation with slightly dilated glomeruli. On combined treatment with rutin and quercetin (Figure: 1h) was nearly similar to normal control group except that there was minimal focal tubular lesion.

\section{DISCUSSION}

There are obvious therapeutic benefits to studying diabetic nephropathy and evaluating novel antidiabetic strategies that are capable of improving the chronic consequences of hyperglycemia. In the present study, STZ-injected rats displayed typical characteristics of diabetes mellitus, such as hyperglycemia, polyuria, growth retardation, proteinuria, renal dysfunction, oxidative stress, and lipid peroxidation. The changes in markers of diabetic nephropathy in our study were consistent with previous report. ${ }^{17-19}$ We also demonstrated in our study that administration of combination of rutin and quercetin could influence these parameters in the diabetic nephropathy rats.

Streptozotocin administration to rats increased plasma glucose and decreased insulin levels. Rutin and quercetin combination treatment in STZ induced diabetic nephritic rats exhibited a decrease in plasma glucose and an increase in insulin levels. Rutin and quercetin by its ability to scavenge free radicals and to inhibit lipid peroxidation, prevents STZ-induced oxidative stress and protects $\beta$-cells resulting in increased insulin secretion and decreased plasma glucose levels. In this context, ${ }^{20}$ have shown that quercetin, the aglycone of rutin decreased blood glucose concentration and increased insulin release in STZ-induced diabetic rats. ${ }^{21}$ have also reported that, in STZ-induced diabetic rats, quercetin protected pancreatic $\beta$-cells by decreasing oxidative stress and preserving pancreatic $\beta$-cell integrity. Increased insulin levels could also be due to the stimulatory effect of rutin, thereby potentiating the existing $\beta$-cells of the islets of Langerhans in diabetic rats.

Measurement of glycated hemoglobin has proven to be particularly useful in monitoring the effectiveness of therapy in diabetes.$^{22}$ The glycated hemoglobin levels increased in diabetic rats with a subsequent decrease in the levels of hemoglobin. Agents with antioxidant or free radical scavenging property may inhibit oxidative reactions associated with glycation. ${ }^{23}$ Rutin and quercetin with its free radical scavenging capability effectively reduced the formation of glycated haemoglobin and increased the total haemoglobin levels in diabetic rats. A decrease in blood glucose levels might also contribute to decreased levels of glycated haemoglobin in rutin and quercetin combination treatment in diabetic nephritic rats.

Diabetic hyperglycaemia induces elevation of the plasma levels of urea, uric acid and creatinine which are considered as significant markers of renal function. ${ }^{24}$ Urea is the major nitrogen containing metabolic product of protein metabolism; uric acid is the major product of purine bases, adenine and guanine; creatinine is endogenously produced and released into body fluids and its clearance is measured as an indicator of glomerular filtration rate. ${ }^{25,26}$ Treatment with rutin and quercetin brought these parameters to near normal level which could be due to decreased disturbances of protein and nucleic acid metabolism as evidenced by improved glycaemic control as well as renal functions. After treatment with rutin and quercetin, we found that 
combination of rutin and quercetin lowered fasting blood glucose and HbA1c of diabetic rats. Blood urea, serum creatinine, urine volume were effectively reduced in combination treatment with rutin and quercetin diabetic nephritic rats compared to diabetic nephritic rats. In this study, combination treatment with rutin and quercetin caused significant improvements in the relative kidney weight, suggesting that they may reverse the hypertrophy in STZ induced diabetic nephritic rats. We concededly demonstrated that combination treatment with rutin and quercetin attenuated diabetic nephritic syndrome characterized by loss of renal function in STZ-diabetic nephritic rats.

Oxidative stress may promote the formation of lipid peroxidation products, increase production of oxygen free radicals thereby reducing the level of antioxidant enzymes. It has been shown previously that increased oxidative stress is related to pathogenesis of diabetes ${ }^{27}$ diabetic renal dysfunction and development of tubulointerstitial injury. ${ }^{28}$ TBARS is a marker of lipid peroxidation and is detected in rats with diabetic nephropathy, and is related to glucose concentration and renal function. Some studies have shown that TBARS is a reliable marker of oxidative stress in renal tissue, and increased levels of TBARS are involved in the occurrence of oxidative stress induced tubular cell damage in diabetic kidneys, and may be possibly used to estimate the severity of renal damage. In the present study, the levels of renal TBARS increased, similarly as in previous studies. In present study, combination treatment of rutin and quercetin decreased TBARS levels in kidney which improves renal impairment in diabetic rats.

Disturbances of antioxidant defense systems in diabetes have been demonstrated, including alteration in the activities of antioxidant enzymes such as superoxide dismutase (SOD), catalase (CAT), glutathione peroxidase $(\mathrm{GPx})$, glutathione reductase (GR) and impaired glutathione (GSH) metabolis. ${ }^{29}$ The antioxidant enzymes SOD, CAT and GPx play an important role in scavenging toxic intermediates of reactive oxygen species. Lipid peroxidation is associated with the changes in the diabetic nephritic shows decreased activities of key antioxidants SOD, CAT and GPx which play an important role in scavenging the toxic intermediate of incomplete oxidation. SOD is the natural cellular antioxidant enzyme; it plays a pivotal role in oxygen defense metabolism by intercepting and reduced superoxide to water and molecular oxygen. ${ }^{30}$ SOD scavenges the superoxide ions produced as cellular byproducts. Catalase is a heme containing ubiquities enzyme, it reduces hydrogen peroxide produced by disputation reaction and preventing generation of hydroxyl radicals thereby protecting the cellular constituents from oxidative damage in peroxisomes.
Decreased activities of both SOD and CAT in diabetic nephritic is due to excess availability of superoxide and hydrogen peroxide $\left(\mathrm{H}_{2} \mathrm{O}_{2}\right)$ in the biological systems which in turn generate hydroxyl and peroxyl radicals, resulting in the initiation and propagation of lipid peroxide. The SOD plays an important role in protecting cells from oxidative damage by converting superoxide radicals into hydrogen peroxide, which is then further metabolized by CAT and GPx, where CAT detoxifies hydrogen peroxide and GPx catalyze the destruction of hydrogen peroxide and lipid hydroperoxide. If the CAT and GPx activity is not sufficiently enhanced to metabolize hydrogen peroxide, this can lead to an increased hydrogen peroxide and TBARS levels. ${ }^{31}$

Non-enzymic antioxidants such as reduced glutathione (GSH) play a vital role in quenching of hyperglycemia mediated free radicals. GSH, being the most important biomolecule against chemically induced toxicity can participate peroxides in the presence of GPx. GSH also functions as free radical scavenger and in the repair of free radical caused biological damage. ${ }^{32} \mathrm{GSH}$, a direct free radical scavenger, also reported to protect the cellular system against the noxious effects of lipid peroxidation. ${ }^{33} \mathrm{GSH}$, a major endogenous antioxidative agent, involve in the conjugation of several types of compounds, protect cells from toxic effects and maintain the cellular redox status. Moreover, reduced glutathione acts as a co-substrate for the activity of glutathione peroxidase and as a cofactor for many enzymes. ${ }^{34}$ The decreased levels of GSH in diabetes could be due to its increased utilization in trapping the oxyradicals. ${ }^{35}$ In our study, diabetic nephritic rats exhibited a decreased level of GSH, which might be due to increased utilization for scavenging free radicals and increased consumption by GPx. Combination treatment of rutin and quercetin increased renal enzymic and non enzymic antioxidants which improves renal impairment in diabetic rats.

Our histological analysis showed that the renal tissues from diabetic animals treated with rutin and quercetin were protected from the damage induced by hyperglycemia. Glomerulosclerosis, hypertrophied distorted glomeruli and dilated tubules with thick basement membranes were significantly inhibited and the fibrotic collagen deposition was prevented by treatment with rutin and quercetin. Extracts can reduce the urine protein levels of patients with DN and thus represents a novel, potentially effective, and safe renoprotective drug for the treatment of $\mathrm{DN}$.

Combination therapy was shown to be significantly better than therapy with the individual agents in renal survival of diabetic patients who have moderately reduced renal function and moderate daily protein excretion. ${ }^{36}$

In conclusion, our results suggest that treatment with combination of rutin and quercetin exerts a beneficial 
effect on diabetic nephropathy via improves antioxidant status, reduced oxidative stress, reduce hyperglycemic conditions and it may be a potential renoprotective pharmaceutical for the treatment of diabetic nephropathy.

\section{ACKNOWLEDGEMENT}

The authors would like to acknowledge Shri Vishnu college of Pharmacy, Andhrapradesh for provided facilities for this study.

\section{REFERENCES}

1. Henry M, Kronenberg MD, Shlomo Melmed MD, Kenneth S. Polonsky MD. Williams's textbook of endocrinology. $12^{\text {th }}$ ed. Philadelphia: Elsevier/ Saunders; 2011. 1371-435

2. McGill M, Felton AM. New global recommendations: a multidisciplinary approach to improving outcomes in diabetes. Global Partnership for Effective Diabetes Management. Prim Care Diabetes. 2007; 1(1): 49-55.

3. Choi R, Kim BH, Naowaboot J, Lee MY, Hyun MR, Cho EJ, Lee ES, Lee EY, Yang YC, Chung $\mathrm{CH}$. Effects of ferulic acid on diabetic nephropathy in a rat model of type 2 diabetes. Exp Mol Med. 2011; 43(12): 676-83.

4. Vijayalakshmi A, Ravichandran A, Malarkodi Velraj V, Nirmala S. Screening of flavanoids quercetin from the rhizome of Smilax china Linn. For psoriatic activity. Asian Pacific J Trop Biomed. 2012; 2(4): 269-75.

5. Trinder P. Determination of blood glucose using 4-amino phenazone as oxygen acceptor. J Clin Pathol. 1969; 22(2): 246

6. Drabkin DL, Austin JH. Spectrophotometric studies: I. Spectrophotometric constants for common hemoglobin derivatives in human, dog, and rabbit blood. J Biol Chem. 1932; 98(2): 719-33.

7. Sudhakar Nayak S, Pattabiraman TN. A new colorimetric method for the estimation of glycosylated haemoglobin. Clin. Chimica Acta. 1981; 109(3): 267-74.

8. Bannon P. Effect of $\mathrm{pH}$ on the elimination of the labile fraction of glycosylated hemoglobin. Clin Chem. 1982; 28(10): 2183.

9. Maha norri hamad. Isolation of rutin from Ruta graveolens cultivated in Iraq by precipitation and fraction solubilization. Int. J. Comprehensive Pharmacy. 2012; 4(01): 1-4.

10. Ohkawa H, Ohishi N, Yagi K. Assay for lipid peroxides in animal tissues by thiobarbituric acid reaction. Anal Biochem. 1979; 95(2): 351-8.

11. Kakkar P, Das B, Viswanathan PN. A modified spectrophotometric assay of superoxide dismutase. Indian J Biochem Biophys. 1984; 21(2): 130-2.

12. Sinha AK. Colorimetric assay of catalase. Anal Biochem. 1972; 47(2): 389-94.

13. Carlberg I, Mannervik B. Glutathione reductase. Methods. Enzymol. 1985; 113: 484-90

14. Flohe L, Günzler WA. Assays of glutathione peroxidase. Methods Enzymol. 1984; 105: 114-21.

15. Ellman GL. Tissue sulfhydryl groups. Arch Biochem Biophys. 1959; 82(1): 70-7.

16. Boyne AF, Ellman GL. A methodology for analysis of tissue sulfhydryl components. Anal Biochem. 1972; 46(2): 639-53.

17. Tripathi AS, Mazumder PM, Chandewar AV. Changes in the pharmacokinetic of sildenafil citrate in rats with Streptozotocin-induced diabetic nephropathy. J Diabetes Metab Disord. 2014; 13(1): 8.
18. Lu HJ, Tzeng TF, Hsu JC, Kuo SH, Chang CH, Huang SY, Chang FY, Wu MC, Liu IM. An aqueous-ethanol extract of Liriope spicata var. prolifera ameliorates diabetic nephropathy through suppression of renal inflammation. Evid Based Complement Alternat Med. 2013; 2013: 201643.

19. Gao C, Aqie K, Zhu J, Chen G, Xu L, Jiang L, Xu Y. MG132 ameliorates kidney lesions by inhibiting the degradation of Smad7 in streptozotocininduced diabetic nephropathy. J Diabetes Res. 2014; 2014: 918396.

20. Vessal M, Hemmati M, Vasei M. Antidiabetic effects of quercetin in streptozotocininduced diabetic rats. Comp Biochem Physiol. 2003; 135: 357-64.

21. Coskun O, Kanter M, Korkmaz A, Oter S. Quercetin, a flavonoid antioxidant, prevents and protects streptozotocin-induced oxidative stress and beta-cell damage in rat pancreas. Pharmacol Res. 2002; 51: 117-23.

22. Goldstein DE. How much do you know about glycated hemoglobin testing? Clin Diab. 1995;13: 60-3.

23. Elgawish A, Glomb M, Freelander M, Monnier VM. Involvement of hydrogen peroxide in collagen cross-linking by high glucose in vitro and in vivo. J Biol Chem. 1996; 271: 12964-71.

24. Almdal JP, Vilstrup $H$. Strict insulin therapy normalizes organ nitrogen contents and the capacity of urea nitrogen synthesis in experimental diabetes in rats. Diabetologia. 1998; 31: 114-8.

25. Burtis CA, Ashwood ER. Enzymes. Fundamentals of Clinical Chemistry, 4th ed. NB Saunders Company, Philadelphia, USA; 1996. 312-35.

26. Perone VB. The natural occurrence and uses of the toxic coumarins. Microb Toxins. 1972; 8: 67-91.

27. Baynes $\mathrm{YW}$, Thorpe R. Role of oxidative stress in diabetic complications. Diabetes. 1999; 48(1): 1-9.

28. Oktem F, Yilmaz HR, Ozguner F, Olgar S, Ayata A, Uzare E, Uz E. Methotrexateinduced renal oxidative stress in rats: The role of a novel antioxidant caffeic acid phenethyl ester. Toxicol and Health. 2006; 22(6): 241-7.

29. 29. Kang J, Dai XS, Yu TB, Wen B, Yang ZW. Glycogen accumulation in renal tubules, a key morphological change in the diabetic rat kidney. Acta Diabetol. 2005; 42(2): 110-6.

30. Lin YF, Tsai HL, Lee YC, Chang SJ. Maternal vitamin E supplementation affects the antioxidant capability and oxidative status of hatching chicks. J. Nutr. 2005; 135(10): 2457-61.

31. Haron D. The aging: Major risk factor for disease and death. Proceedings of the Natural Academy of Sciences USA. 1991; 88(12): 5360-4.

32. Pinakini K, Shankar, Vasanth Kumar, Namita Rao. Evaluation of antidiabetic activity of ginkgo biloba in streptozotocin induced diabetic rats. Iran. J. Pharmacol Ther. 2005; 4: 16-9.

33. Whiting PH, Kalansooriya A, Holbrook I, Haddad F, Jennings PE. The relationship between chronic glycaemic control and oxidative stress in type 2 diabetes mellitus. Br. J. Biomed. Sci. 2008; 65(2): 71-4.

34. Maritim AC, Sanders RA, Watkins JB. Effects of a-lipoic acid on biomarkers of oxidative stress in streptozotocin-induced diabetic rats. J. Nutr. Biochem. 2003; 14: 288-94.

35. Murugan P, Pari L. Effect of tetrahydrocurcumin on plasma antioxidants in streptozotocin- nicotinamide experimental diabetes. J. Basic Clin. Physiol. Pharmacol. 2006; 17(4): 231-44.

36. Jia ZH, Liu ZH, Zheng JM, Zeng CH, Li LS. Combined therapy of rhein and benazepril on the treatment of diabetic nephropathy in $\mathrm{db} / \mathrm{db}$ mice. Exp Clin Endocrinol Diabetes. 2007; 115(9): 571-6. Equias ut plam, qui occus. 